\title{
Design-driven repair: understanding ancient and contemporary product repair practices in Latin America
}

\author{
Ricardo J Hernandez ${ }^{a^{*}}$, Julian Goñia, Tracy Bhamrac \\ aDILAB School of Engineering, Pontificia Universidad Católica de Chile, Santiago, Chile

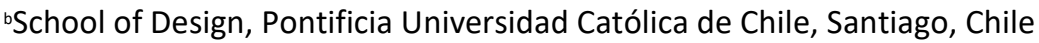 \\ 'Royal Holloway, University of London, London, United Kingdom \\ *Corresponding author e-mail: rhernandep@uc.cl
}

\begin{abstract}
:
Repair is presented as one of the desirable strategies in the framework to develop the Circular Economy (Ellen MacArthur Foundation, 2012). However, not many products which are suitable to be repaired are in fact actually repaired. Products end up in landfills or are incinerated when they still have value to deliver. From a design perspective, technical issues have been addressed and there are actions that can facilitate product repair. Despite these actions, there are other issues related to the desire and emotions involved in the process of repairing that have not been thoroughly studied in a design context. This paper investigates ancient and contemporary repair practices aiming to understand the motivations, obstacles, and conditions that could highlight opportunities to intervene early in the design process to favour product repairability based on social and cultural issues beyond the technical concerns that have already been taken into consideration.
\end{abstract}

Keywords: design; repair; circular economy; regenerative culture

\section{Circular Economy}

A Circular Economy is supported by biological and technical cascades in which products circulate to assure all the value is extracted from them before their final disposal, and residual materials return to the earth not causing harm (Ellen MacArthur Foundation, 2012; European Commission, 2020; Kok, Wurpel, \& Ten Wolde, 2013). This new production and consumption logic proposes to keep "products, components, and materials at the higher utility and value at all times" (Bjørnbet, Skaar, Fet, \& Schulte, 2021; Ellen MacArthur Foundation, 2012; Masi, Kumar, Garza-Reyes, \& Godsell, 2018). The concept of Circular Economy collects the insights and ideas of previous approaches such as cradle-to-cradle (Braungart \& McDonough, 2002), eco-efficiency, sustainable product-service systems (Gottberg, Longhurst, \& Cook, 2010; Hernandez, 2019; Hernandez, Bhamra, \& Bhamra, 2012; Manzini \& Vezzoli, 2002; Mont, 2002), and design for sustainability (Bhamra \& Hernandez, 
2021; Bhamra, Hernandez, \& Mawle, 2013; Bhamra \& Lofthouse, 2007), and present them in a comprehensive framework to businesses desiring to make a transition or to initiate themselves a circular business model (Moreno, De los Rios, Rowe, \& Charnley, 2016; Nußholz, 2017). Acceptance levels have been very promising, especially among large businesses and policy makers (Bjørnbet et al., 2021; Ellen MacArthur Foundation, 2016; Enkvist \& Klevnas, 2018). In general, important environmental and social benefits are recognized in a circular economy and it is currently the most likely concept to help to achieve a more sustainable society (Enkvist \& Klevnas, 2018; Moreno et al., 2016).

Focusing on the technical side of this discussion four main strategies are presented as the basis of the continuing circulation of products: reuse, repair, remanufacturing and recycling (Ellen MacArthur Foundation, 2012; Mestre \& Cooper, 2017). The fewer resources that are needed to maintain products circulating in the system the better the strategy is (Blomsma et al., 2019; Hernandez, Miranda, \& Goñi, 2020). In this sense the preferred option is to reuse products without investing further resources in them other than cleaning and low maintenance supplies (Bakker, Mugge, Boks, \& Oguchi, 2021). Repair is the next most desirable option, in which products require small fixes to continue delivering their value and fulfilling their original function (Bakker et al., 2021; Blomsma et al., 2019). Remanufacturing is a strategy that involves major interventions in the products, usually changing parts and even updating functionalities (Bakker et al., 2021; Blomsma et al., 2019). Finally comes recycling, an option frequently selected as the way to deal with a product after its use (Goodship, 2007), however, in reality it should be the last option and then only for products that have already circulated through the system many times, and where there are no other alternatives.

Design plays a major role in developing products that will perform successfully under reuse, repair, remanufacturing, and recycling scenarios (De los Rios \& Charnley, 2017; Hernandez, 2019; Lofthouse \& Prendeville, 2018; Nogueira, Ashton, \& Teixeira, 2019). The Ellen MacArthur Foundation recognizes design are one of the building blocks of the Circular Economy (Ellen MacArthur Foundation, 2012). Its influence is associated with the direct design of products but also with the design of business models that support these new types of products (Nußholz, 2017; Sumter, de Koning, Bakker, \& Balkenende, 2020).

\section{Design Driven Repair}

Between the technical strategies proposed in the Circular Economy, repairability is a very interesting alternative that can encourage consumers to keep their products for longer before they dispose of them (Ackermann, 2018; Lee \& Wakefield-Rann, 2021; Nazlı, 2021). Despite the common sense that comes with the idea of repairing before replacing old products that still have value, the reality is that repair has declined significantly in recent years (Jaeger-Erben, Frick, \& Hipp, 2021; Nazlı, 2021). Perverse market incentives and technical issues have inhibited consumers to repair their products, such as lack of repair centres, difficulty to find parts and tools, lower prices of new low-quality products, intellectual property, and poor designs for example (Grafström \& Aasma, 2021; Hernandez et al., 2020; Laitala, Klepp, Haugrønning, Throne-Holst, \& Strandbakken, 2021; Svensson-Hoglund et al., 2021).

Before the Circular Economy was a popular concept within academic research and industry, there were significant advances in repairability in areas of study such as eco-design, ecoefficiency, and design for sustainability (Bhamra \& Hernandez, 2021; Bhamra \& Lofthouse, 2007; Kim, Cluzel, Leroy, Yannou, \& Yannou-Le Bris, 2020). In this context concepts such as design for disassembly, design for repair, design for serviceability, or design for maintainability have contributed to make product 
repair more feasible from a technical perspective (Sassanelli, Urbinati, Rosa, Chiaroni, \& Terzi, 2020). Not all of these approaches were aimed explicitly to produce positive impacts on the environmental or social performance of products, some emerged to increase efficiency and productivity, but in general all have contributed to make products more repairable.

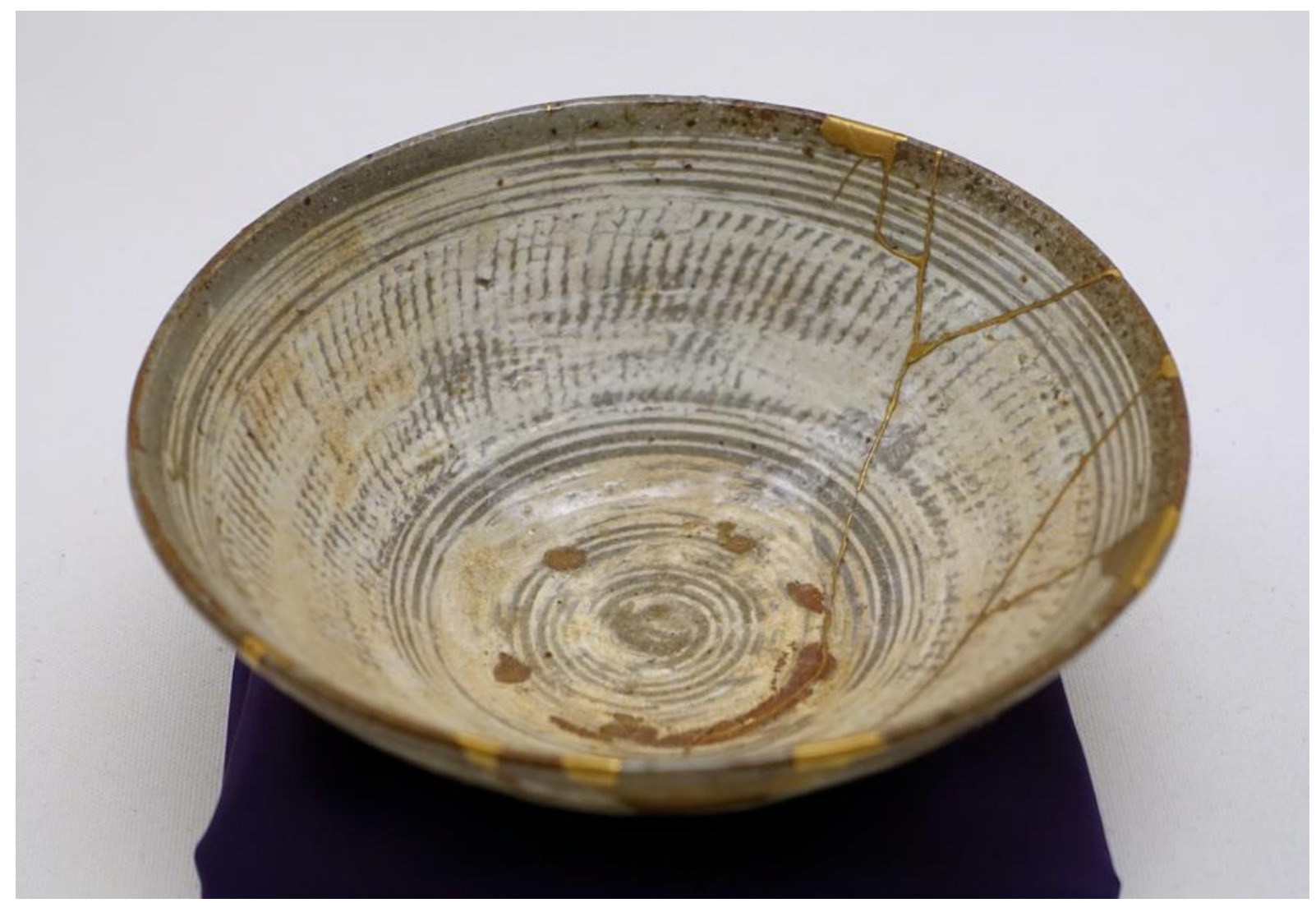

Figure 1. Example of pottery repaired following the Kintsugi practice. Daderot. (2014)

Despite the technical opportunities that design can embed in a product to make it more repairable (Cordella, Alfieri, Clemm, \& Berwald, 2021; Laitala et al., 2021), the fact is that for different reasons nowadays repair is not the first alternative users consider when a product fails (Jaeger-Erben et al., 2021; Laitala et al., 2021; Nazlı, 2021; Svensson-Hoglund et al., 2021). Beyond technical obstacles to repair there are other issues related to the desires, emotions, and motivations of consumers that should drive product repair that are not totally understood from a product design perspective (Jaeger-Erben et al., 2021; Laitala et al., 2021; Nazlı, 2021). There are historical examples of practices like Kintsugi in Japan (Keulemans, 2016; Mentesana, De Benedetto, \& Fiorentino, 2018), where repairing a product is considered an art. Scars of broken pieces of pottery are fixed and decorated with gold making the repaired product even most valuable than the original one (economically and emotionally) (Bridgens, Lilley, Zeilig, \& Searing, 2019; Buetow \& Wallis, 2019). But what motivates people to invest and to dedicate time and effort to bring a broken cup back to life in this ceremonial way? What are the motivations that lead users to prefer a repaired product over a new one? How can we avoid the typical view that a repaired product has value less than a new one?

In this paper we address these and other related questions to explore the role that design can play to encourage product repairability beyond the technical aspects. In order to do so, we first explore two case studies to recognise the characteristics that have made repair popular at certain times and in particular geographical locations, and also explore current views on repairability. The aim of this 
paper is to illustrate how product repairability can be motivated and facilitated through decisions made early in the design process. Decisions motivated by cultural and social issues that can affect tangible and intangible features of the product.

\section{Exploration of Case Studies}

In this paper, we will explore and compare two different case studies (Yin, 2012) of repair practices in two very different time periods of Latin American. To construct these case studies, we used publicly available secondary data (Reddy \& Agrawal, 2012). Both case studies reflect culturally rich repair experiences originating from Latin America. In this article, we will present the document analysis originating from secondary sources in the expectations that this will be blended with qualitative interviews (Owen, 2014) in a larger publication.

\subsection{Case 1: Ancient repair practices in northern South America}

Until quite recently, not much was known about the so-called 'early' or 'ancient' repair practices of Latin-American indigenous communities, as much of the anthropological attention has been focused on Europe, Middle East and Asia (Rodríguez Larrota, 2019). Perhaps one the most substantial efforts to document Latin American traditional repair practices was conducted by the Colombian Museo del Oro (Museum of Gold) that culminated in the 2018 series of expositions, conferences and public engagement activities called "Esto tiene arreglo" (This can be fixed). Throughout the documentation conducted by the Museum, many insights can be drawn about the cultural dimensions of object repair in prehispanic Latinamerica (200BC -1600AD).

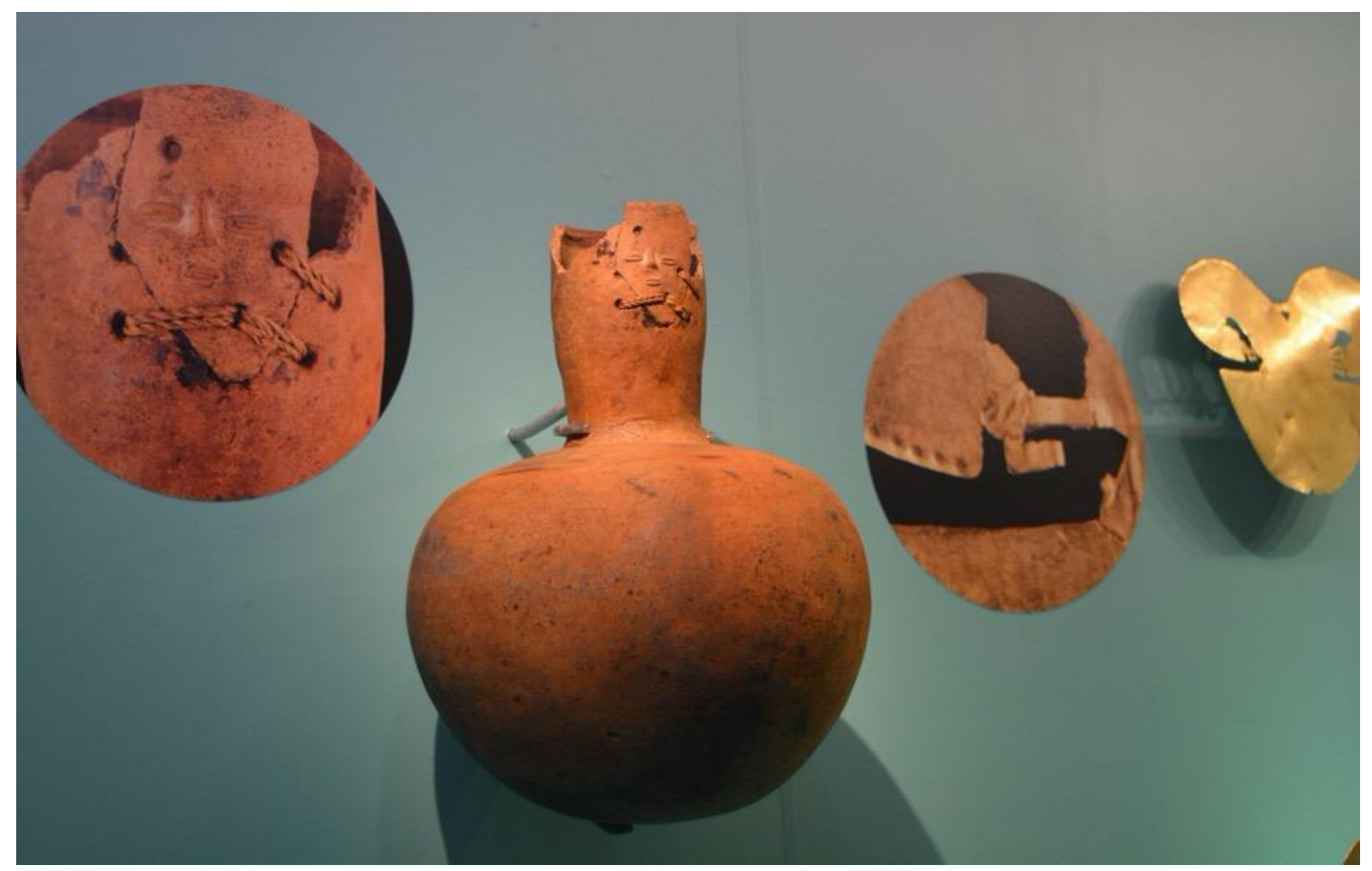

Figure 2. Example of pottery repaired in ancient Latin American communities. Banco de la Republica (2018) 
The case of the cast filigree earrings from the Zenú archaeological area (Gómez Forero, Valencia Andrade, \& Obando Arango, 2019) and the pre-hispanic pottery repairs in Colombia describes the technical proficiency of the materials and techniques used in product repair (Rodríguez Larrota, 2019). These ancient techniques were often used to integrate missing pieces into valuable objects from everyday life or from ceremonial usage. Among the documented repair techniques, the research includes the displacement of strands, selective hammering, addition of inter-weave metal, and dripping of the cast metal. In terms of materials, one of the main findings of the pottery repair case study is the widespread use and efficiency of bee wax in the repair process.

According to the analysis, most repairs used the same tools used for manufacturing and mostly at the same location. This documentation shows the advanced technologies of repair used by the indigenous Latin American people (Gómez Forero et al., 2019) and its social organization as a communal endeavor. These examples of pre-hispanic repair help to map the technical choices used by ancient communities, but also serve as a reminder of the value of imperfection that was inscribed into repaired objects, both in this context and other documented cases (Rodríguez Larrota, 2019).

Two additional findings can be extracted from these case studies. Firstly, that Latin American indigenous communities held a notable but mostly ignored tradition of product repair. Secondly, that despite these initial efforts, more research is needed to illuminate how these ancient repair practices were embedded in cultural value systems, economics and ideology (Rodríguez Larrota, 2019). As Gómez Forero et al. (2019) assert: "If an object suffers deterioration or damage at some point in its history, discarding it or not will depend not only on the decision of its creator or owner, but on its meaning, the affection that it has, its utility or the technical complexity that its elaboration implied" (p.59).

In summary, these ancient repair experiences offer a great learning experience for contemporary repair practices. On the one hand, they illustrate the socio-technical complexity of repair practices, that in this case, reflect a community driven mentality in which the manufacturing of products was directly related to its repair. On the other hand, they offer a set of ancient traditions, including repair techniques and materials, that need to be further explored, but can inspire contemporary ways to reimagine and re-design repair practices in the spirit of reconnecting with the indigenous knowledge that continues to influence Latin-American culture.

\subsection{Case 2: Club de Reparadores (Argentina)}

There are multiple ways a product can be repaired nowadays. It can happen in repair centres offered directly by producers, it can be done by third parties, a neighbourhood repairman, or directly by users. In all forms of repair, mass consumer products are repaired less now than some decades ago (Jaeger-Erben et al., 2021; Laitala et al., 2021). However, directives such as the "right to repair" promoted in the European Union have grown the interest in product repair for its economic, environmental and social benefits. Another force driving product repair into practice has been the community meetings to repair (Club de Reparadores, 2021; Repair Cafe, 2021). Between these social initiatives to repair, one recognized as a pioneer is the Repair Cafes Initiative (Normoyle \& Tegtmeyer, 2017). It was born in Amsterdam around 2007 promoted by Martine Postma (Repair Cafe, 2021).

In these repair meetings, people gather together to repair their products, including electric and electronic appliances, clothes, toys, and bicycles, amongst other things. Organisers usually provide materials and tools to repair, and they invite expert volunteers (Repair Cafe, 2021). In South America, 
one of these initiatives is the "Club de Reparadores" in Argentina (Galluzzo, 2021), it was founded in 2015 by Mariana Pla and Melina Scioli, inspired by previous experiences like the Repair Cafes in Europe (Club de Reparadores, 2021). This "Club" is an itinerant event run at different locations in the country focused on electric and electronic appliances and textiles (Winwins Argentina, 2017).

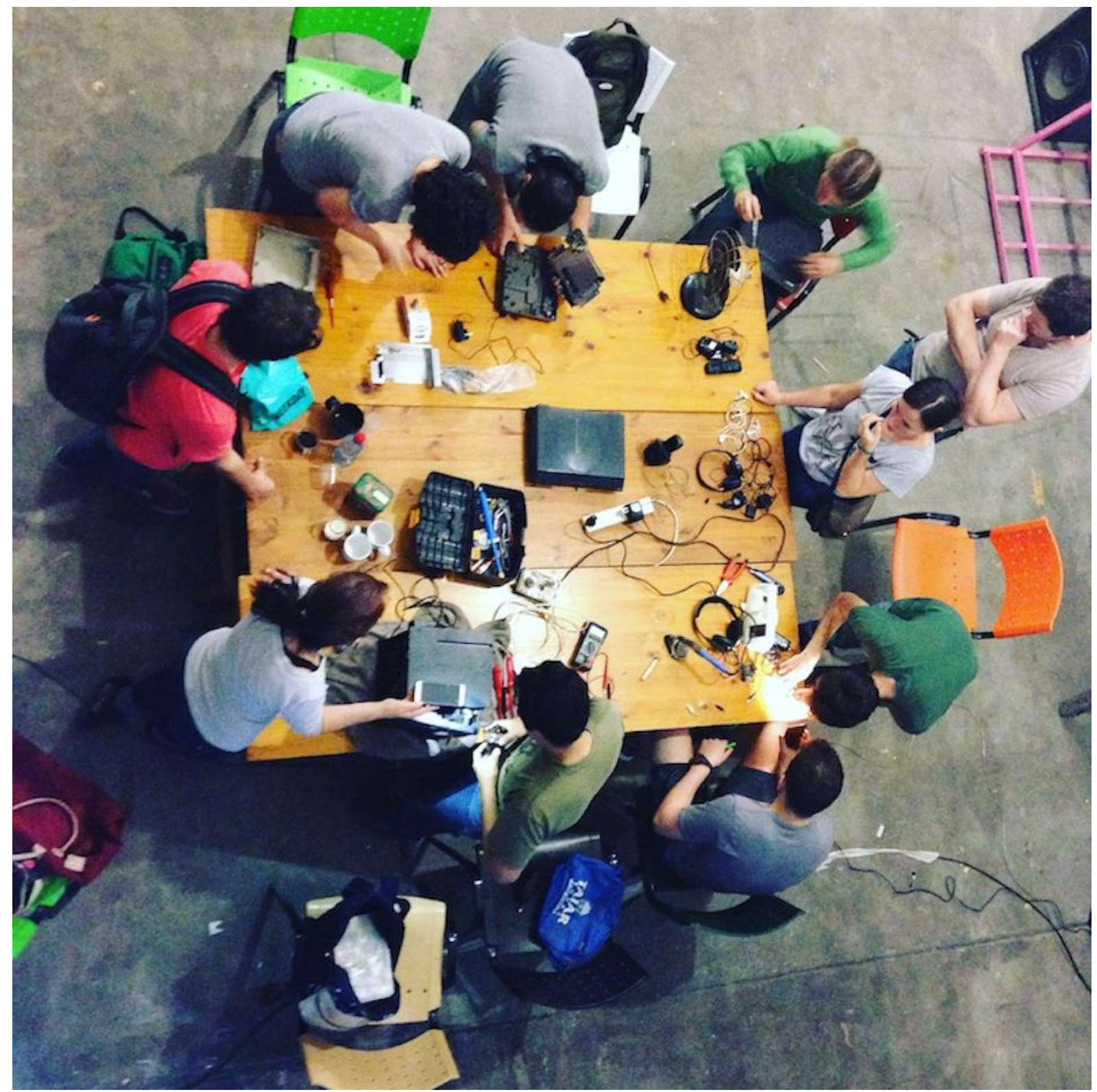

Figure 3. Gathering at one event of Club de Reparadores. Source: Club de Reparadores

Analysing the strategic interests declared by the founders and their manifesto, it is possible to see the motivations they want to push forward, the obstacles they see in product reparation and the benefits it can produce. Between the most straight forward motivations declared by the founders, there is the fact that repair is one way to extend the product life span and reduce waste (Club de Reparadores, 2021). They recognize the value product repair has as a technical strategy part of the circular economy framework. There is a clear vision that positions product repair as a sustainable practice (Club de Reparadores, 2021). Interestingly, their motivation to organise these events goes beyond the environmental impact they can reduce. It is mentioned that these events aim to build community relationships, generate employment for local repairers, promote innovative technologies 
like 3D printing, revalue traditional trades (Winwins Argentina, 2017), and fight against planned obsolescence (Club de Reparadores, 2021).

Concerning the perception people who attend these events have of repaired products, the Club of Reparadores declare that one of their objectives is to give value to the relationship people have with their objects. They even mention the idea that objects should pass from one generation to the next one (Club de Reparadores, 2021). There is also the implicit idea that repair empowers people, for example, sharing in an open-source fashion what is learnt during the repair events. Mariana Pla mentions the lack of knowledge as one of the obstacles people face when they want to repair (Winwins Argentina, 2017).

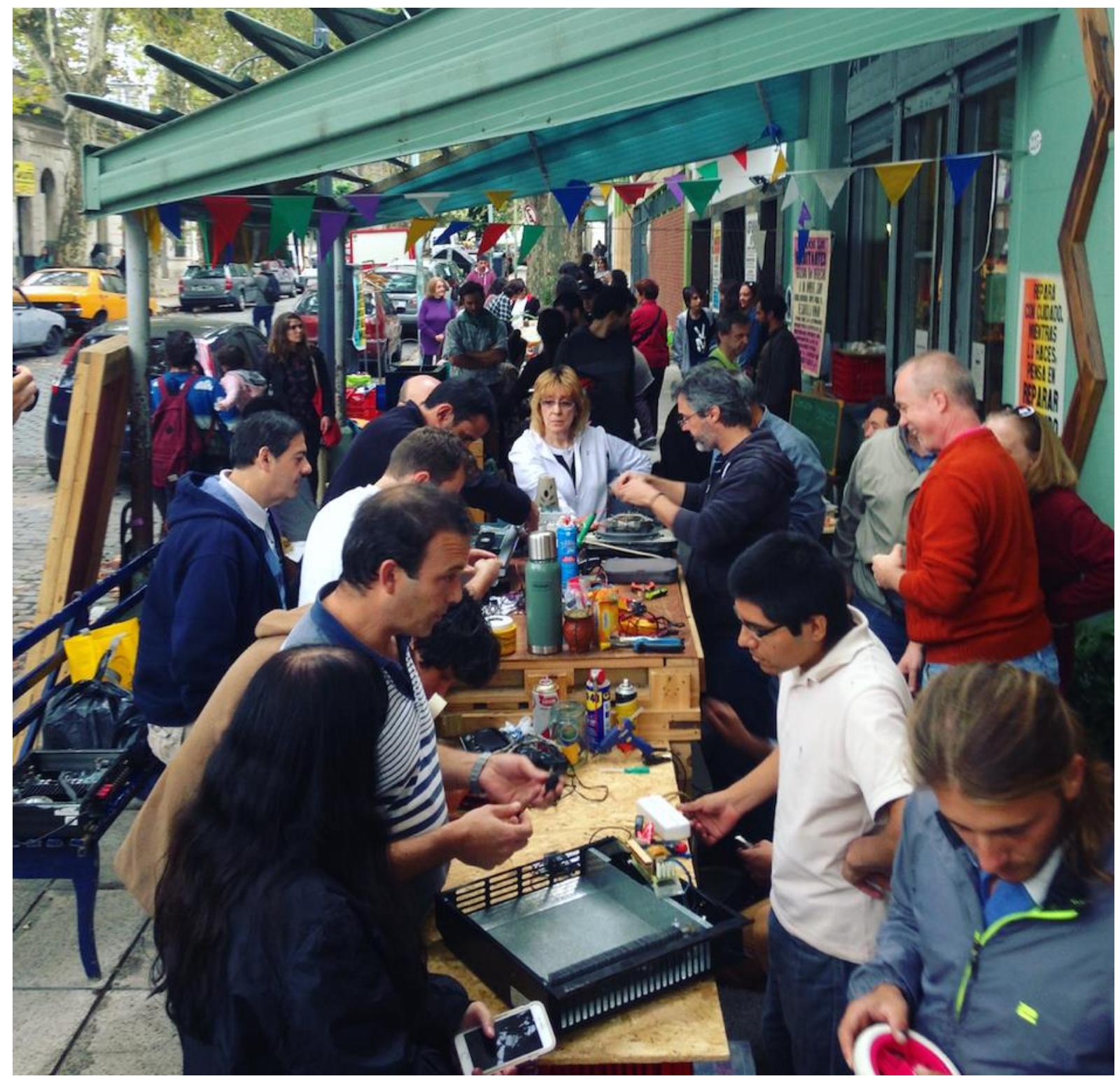

Figure 4. In the events organised by the Club de Reparadores, different actors of the community come to work together: volunteers, repairers, neighbours. Source: Club de Reparadores

In conclusion, social gatherings to repair products, such as the ones organized by the Club de Reparadores, have interesting cultural aspects that go beyond the reduction in waste that results from product repair due to the extension of the product's life. Multiple socio-technical aspects in 
these repair events align with having a regenerative culture based on value greater than the resources embedded in the products, building communities, empowering people, and creating sustainable lifestyles. How much of these motivations and efforts can be translated to other spaces of contemporary repair, and what is the real impact these gatherings have in terms of numbers of products repaired are questions that have to be addressed in further investigations.

\section{Discussion}

The two case studies explored in this paper share parallels and interesting tensions. In both cases, they observe how both ancient and contemporary cultures of repair are often time driven by engaged communities and embedded in socio-technical practices that reflect on a society's technologies, habits and social norms. Whether using bees wax or 3D printing, people repair in their communities because they care about their objects.

The case of "Club de Reparadores" adds clear political connotations in their imagination of repair. To repair is to fight against unsustainable manufacturing processes, a way to re-value traditional jobs, a way to educate consumers and to empower people in a broad sense. The meaning of repair to the pre-Hispanic indigenous communities in Latin America is still understudied. Still, at the very least, we can infer from their material legacy that the products' repairs were visible and noticeable because they reflect on a culture in which imperfection was considered, and repair was an established practice even if we don't know the exact meaning of it.

Some interesting contrasts can also be made when comparing both cases. Table 1 summarizes the preliminary findings of this research project contrasting these two different contexts of LatinAmerican repair. This table displays what sorts of tenets, processes and symbolisms were embedded in the two cases. "Club de Reparadores" is conceived as a nod to a much larger universal and international experience. In this sense, it is the 'importation' of a repair ideal that has its roots in northern Europe. The leaders of the Club have notably done an interesting job in integrating that format into the aspirations and struggles of their own communities, but from the perspective of design decolonization there may be lessons to extract from indigenous and local knowledge in order to bring about fully culturally-driven repair. Can we re-interpret the way we design repair experiences integrating techniques and materials from our cultural heritage and emergent technologies invented internationally? Can we extract practical wisdom from the social organization of repair in traditional communities (for instance, in the close spatial connection between manufacturing and repair)? Can we manage to even 'export' design-driven repair ideas to the world and thus re-situating Latin America as a knowledge producer rather than just consumer?

Table 1

Comparison of the two case studies regarding main emphasis given

\begin{tabular}{|l|l|l|}
\hline & $\begin{array}{l}\text { Ancient repair in Northern } \\
\text { Latin America }\end{array}$ & Club de Reparadores \\
\hline Reasons to repair & $\begin{array}{l}\text { Psychosocial: Extend the } \\
\text { lifespan of valuable objects }\end{array}$ & $\begin{array}{l}\text { Ecological reasons: Extend } \\
\text { lifespan of products and } \\
\text { reduce waste } \\
\text { Economical: Save money when } \\
\text { buying new products }\end{array}$ \\
\hline
\end{tabular}




\begin{tabular}{|l|l|l|}
\hline & & $\begin{array}{l}\text { Political: Revalorize repair jobs } \\
\text { in the country and fight against } \\
\text { perverse principles like design } \\
\text { for obsolescence }\end{array}$ \\
\hline Repair design & $\begin{array}{l}\text { Integrated with the } \\
\text { manufacturing process } \\
\text { Communal endeavour } \\
\text { Making damage visible }\end{array}$ & $\begin{array}{l}\text { Driven by emergent } \\
\text { technologies } \\
\text { Collaborative and horizontal } \\
\text { Integrating repair workers }\end{array}$ \\
& $\begin{array}{l}\text { Sharing knowledge and skills to } \\
\text { empower products' owners }\end{array}$ \\
\hline The repaired object & $\begin{array}{l}\text { Value in imperfection } \\
\text { Valued by the resources and } \\
\text { time embedded into it }\end{array}$ & $\begin{array}{l}\text { Same as the original } \\
\text { Value in recovering the } \\
\text { object's functionality } \\
\text { Emotionally attached }\end{array}$ \\
\hline
\end{tabular}

As table 1 describes, there are many complementing elements and joint lessons to be drawn from both cases. We propose that design may offer a way of addressing, expanding and critically examining this complexity exhibited by the cases. A design-driven repair agenda that is centred on decolonization and democratization can find ways to integrate the old and the new, the local and the external, the technical and the symbolical. Through design, this experimentation can lead to new products, services and systems to engage people with repair and raise awareness of the fact that the way in which we care about our objects speaks about who we are and where we are heading.

In particular, we observed that a Latin-American agenda for design-driven repair should address the challenges of rethinking the way we repair through reconstructing repair as a communal endeavour, as our firsts people did, and a process that highlights the passing of time and transformation of matter instead of hiding it. However, it should not be indifferent to the global challenges, such as sustainability or the new possibilities given by emergent technologies. As emphasized by El Club de Reparadores, this task should also make use of the expertise of our local repair professionals and think about how to excite newer generations not accustomed to product repair. In sum, we see the Latin-American agenda for design-driven repair as one needing design for creating experiences, for re-imagining productive processes, for making cultural critic and re-designing products in a manner that can produce this image and be guided by these cultural values.

Design-driven repair can become a powerful path to achieve technical benefits based on the continuing circulation of products. It also has the potential to change our mindset towards more sustainable lifestyles. Still, to capitalize on that opportunity, it has to consider the traditions and socio-cultural aspects that shape repair practices, motivations and obstacles that differ between territories and communities. A real, more sustainable future cannot be imposed as has been the case with other ideas in the past. There is a great challenge to produce design tools and frameworks that can orient the design of products that facilitates and propitiates repair, integrating technical and non-technical aspects considering local knowledge and cultural identity.

Comparing ancient repair practices with current communitarian efforts aiming to increase the number of people involved in product repair is part of the path we should follow to understand 
better the conditions required to establish repair as a common practice. Beyond ecological gains, product repair is a sensible way to manage our relationship with our material environment. It can potentially change the way we satisfy our needs in a manner better aligned with the preferable future we enunciated in the late 80 s when the term "sustainable development" was first coined.

\section{References}

Ackermann, L. (2018). Design for Product Care: Enhancing Consumers' Repair and Maintenance Activities. The Design Journal, 21(4), 543-551. https://doi.org/10.1080/14606925.2018.1469331

Bakker, C. A., Mugge, R., Boks, C., \& Oguchi, M. (2021). Understanding and managing product lifetimes in support of a circular economy. Journal of Cleaner Production, 279, 123764. https://doi.org/10.1016/j.jclepro.2020.123764

Bhamra, T., \& Hernandez, R. J. (2021). Thirty years of design for sustainability: an evolution of research, policy and practice. Design Science, 7, e2. https://doi.org/10.1017/dsj.2021.2

Bhamra, T., Hernandez, R. J., \& Mawle, R. (2013). Sustainability: Methods and Practices. In The Handbook of Design for Sustainability (pp. 106-120). Bloomsbury Publishing Plc.

Bhamra, T., \& Lofthouse, V. (2007). Design for sustainability: A practical approach (R. Cooper, Ed.). Gower Publishing Limited.

Banco de la República. (2018). ¿Esto tiene arreglo? Cómo y por qué reparamos las cosas. Flickr. Retrieved May 22, 2021. https://www.flickr.com/photos/banrepcultural/28773703598/in/album-72157669877149998/ CC BY-SA 2.0 license.

Bjørnbet, M. M., Skaar, C., Fet, A. M., \& Schulte, K. Ф. (2021). Circular economy in manufacturing companies: A review of case study literature. Journal of Cleaner Production, 294, 126268. https://doi.org/10.1016/j.jclepro.2021.126268

Blomsma, F., Pieroni, M., Kravchenko, M., Pigosso, D. C. A., Hildenbrand, J., Kristinsdottir, A. R., ... McAloone, T. C. (2019). Developing a circular strategies framework for manufacturing companies to support circular economy-oriented innovation. Journal of Cleaner Production, 241, 118271. https://doi.org/10.1016/j.jclepro.2019.118271

Braungart, M., \& McDonough, W. (2002). Cradle to Cradle: Remaking the way we make things. New York: North Point Press.

Bridgens, B., Lilley, D., Zeilig, H., \& Searing, C. (2019). Skin deep. Perceptions of human and material ageing and opportunities for design. The Design Journal, 22(sup1), 2251-2255. https://doi.org/10.1080/14606925.2019.1595022

Buetow, S., \& Wallis, K. (2019). The Beauty in Perfect Imperfection. Journal of Medical Humanities, 40(3), 389-394. https://doi.org/10.1007/s10912-017-9500-2

Club de Reparadores. (2021). Club de Reparadores. Retrieved May 10, 2021, from http://reparadores.club/

Cordella, M., Alfieri, F., Clemm, C., \& Berwald, A. (2021). Durability of smartphones: A technical analysis of reliability and repairability aspects. Journal of Cleaner Production, 286, 125388. https://doi.org/10.1016/j.jclepro.2020.125388

Daderot (2014). Exhibit in the Ethnological Museum, Berlin, Germany. Photography was permitted in the museum without restriction. Wikimedia Commons. Retrieved May 22,

2021. https://commons.wikimedia.org/wiki/File:Tea_bowl,_Korea,_Joseon_dynasty,_16th_centur Y_AD,_Mishima-

hakeme_type,_buncheong_ware,_stoneware_with_white_engobe_and_translucent,_greenishgray_glaze,_gold_lacquer_-_Ethnological_Museum,_Berlin_-_DSC02061.JPG

De los Rios, I. C., \& Charnley, F. J. S. (2017). Skills and capabilities for a sustainable and circular economy: The changing role of design. Journal of Cleaner Production, 160, 109-122. 
https://doi.org/https://doi.org/10.1016/j.jclepro.2016.10.130

Ellen MacArthur Foundation. (2012). Towards the Circular Economy: Economic and business rationale for an accelerated transition.

Ellen MacArthur Foundation. (2016). The New Plastics Economy: Rethinking the future of plastics.

Enkvist, P.-A., \& Klevnas, P. (2018). The Circular Economy. A Powerful Force for Climate Mitigation: Transformative Innovation for Prosperous and Low Carbon Industry. Stockholm: Material Economics Sverige AB.

European Commission. (2020). A new Circular Economy Action Plan: For a cleaner and more competitive Europe.

Galluzzo, M. (2021). "It's your device, you should be able to repair it." BBC News. Retrieved from https://www.bbc.com/news/business-56799069

Gibbons, L. V. (2020). Regenerative-The New Sustainable? Sustainability, 12(13), 5483. https://doi.org/10.3390/su12135483

Gómez Forero, M. de la P., Valencia Andrade, J. S., \& Obando Arango, P. F. (2019). Hallazgo y caracterización de reparaciones tempranas en orejeras de filigrana fundida zenú de la colección del Museo del Oro. Boletín Museo Del Oro, 58, 57-99.

Goodship, V. (2007). Plastic Recycling. Science Progress, 90(4), 245-268. https://doi.org/10.3184/003685007X228748

Gottberg, A., Longhurst, P. J., \& Cook, M. B. (2010). Exploring the potential of Product Service Systems to achieve household waste prevention on new housing developments in the UK. Waste Management \& Research : The Journal of the International Solid Wastes and Public Cleansing Association, ISWA, 28(3), 228-235. https://doi.org/10.1177/0734242X09103837

Grafström, J., \& Aasma, S. (2021). Breaking circular economy barriers. Journal of Cleaner Production, 292, 126002. https://doi.org/10.1016/j.jclepro.2021.126002

Hernandez, R. J. (2019). Sustainable Product-Service Systems and Circular Economies. Sustainability, 11(19), 5383. https://doi.org/10.3390/su11195383

Hernandez, R. J., Bhamra, T., \& Bhamra, R. (2012). Sustainable Product Service Systems in Small and Medium Enterprises (SMEs): Opportunities in the Leather Manufacturing Industry. Sustainability, 4(2), 175-192. https://doi.org/10.3390/su4020175

Hernandez, R. J., Miranda, C., \& Goñi, J. (2020). Empowering Sustainable Consumption by Giving Back to Consumers the 'Right to Repair.' Sustainability, 12(3), 850. https://doi.org/10.3390/su12030850

Jaeger-Erben, M., Frick, V., \& Hipp, T. (2021). Why do users (not) repair their devices? A study of the predictors of repair practices. Journal of Cleaner Production, 286, 125382. https://doi.org/10.1016/j.jclepro.2020.125382

Keulemans, G. (2016). The Geo-cultural Conditions of Kintsugi. The Journal of Modern Craft, 9(1), 1534. https://doi.org/10.1080/17496772.2016.1183946

Kim, H., Cluzel, F., Leroy, Y., Yannou, B., \& Yannou-Le Bris, G. (2020). Research perspectives in ecodesign. Design Science, 6, e7. https://doi.org/10.1017/dsj.2020.5

Kok, L., Wurpel, G., \& Ten Wolde, A. (2013). Unleashing the Power of the Circular Economy. Amsterdam.

Laitala, K., Klepp, I. G., Haugrønning, V., Throne-Holst, H., \& Strandbakken, P. (2021). Increasing repair of household appliances, mobile phones and clothing: Experiences from consumers and the repair industry. Journal of Cleaner Production, 282, 125349. https://doi.org/10.1016/j.jclepro.2020.125349

Lee, T., \& Wakefield-Rann, R. (2021). Conspicuous and inconspicuous repair: A framework for situating repair in relation to consumer practices and design research. Journal of Cleaner Production, 294, 126310. https://doi.org/10.1016/j.jclepro.2021.126310

Lofthouse, V., \& Prendeville, S. (2018). Human-Centred Design of Products And Services for the Circular Economy - A Review. The Design Journal, 21(4), 451-476. https://doi.org/10.1080/14606925.2018.1468169

Manzini, E., \& Vezzoli, C. (2002). Product Service Systems and Sustainability. Retrieved from 
http://www.unep.org/resourceefficiency/Portals/24147/scp/design/pdf/pss-imp-7.pdf

Masi, D., Kumar, V., Garza-Reyes, J. A., \& Godsell, J. (2018). Towards a more circular economy: exploring the awareness, practices, and barriers from a focal firm perspective. Production Planning \& Control, 29(6), 539-550. https://doi.org/10.1080/09537287.2018.1449246

Mentesana, R., De Benedetto, G., \& Fiorentino, G. (2018). One Pot's tale: reconstructing the movement of people, materials and knowledge in Early Bronze Age Sicily through the microhistory of a vessel. Journal of Archaeological Science: Reports, 19, 261-269. https://doi.org/10.1016/j.jasrep.2018.03.003

Mestre, A., \& Cooper, T. (2017). Circular Product Design. A Multiple Loops Life Cycle Design Approach for the Circular Economy. The Design Journal, 20(sup1), S1620-S1635. https://doi.org/10.1080/14606925.2017.1352686

Mont, O. (2002). Drivers and barriers for shifting towards more service-oriented businesses: Analysis of the PSS field and contributions from Sweden. The Journal of Sustainable Product Design, 2, 89-103.

Moreno, M., De los Rios, C., Rowe, Z., \& Charnley, F. (2016). A Conceptual Framework for Circular Design. Sustainability, Vol. 8. https://doi.org/10.3390/su8090937

Nazlı, T. (2021). Repair motivation and barriers model: Investigating user perspectives related to product repair towards a circular economy. Journal of Cleaner Production, 289, 125644. https://doi.org/10.1016/j.jclepro.2020.125644

Nogueira, A., Ashton, W. S., \& Teixeira, C. (2019). Expanding perceptions of the circular economy through design: Eight capitals as innovation lenses. Resources, Conservation and Recycling, 149, 566-576. https://doi.org/10.1016/j.resconrec.2019.06.021

Normoyle, C., \& Tegtmeyer, R. (2017). Speculating the Possibilities for Remote Collaborative Design Research. The Experimentations of a Drawing Robot. The Design Journal, 20(sup1), S4038S4051. https://doi.org/10.1080/14606925.2017.1352906

Nußholz, J. (2017). Circular Business Models: Defining a Concept and Framing an Emerging Research Field. Sustainability, 9(10), 1810. https://doi.org/10.3390/su9101810

Owen, G. (2014). Qualitative Methods in Higher Education Policy Analysis: Using Interviews and Document Analysis. The Qualitative Report, 19. https://doi.org/10.46743/2160-3715/2014.1211

Reddy, K. S., \& Agrawal, R. (2012). Designing Case Studies from Secondary Sources - A Conceptual Framework. SSRN Electronic Journal, 8(2). https://doi.org/10.2139/ssrn.2167776

Repair Cafe. (2021). Repair Cafes. Retrieved May 10, 2021, from https://www.repaircafe.org

Rodríguez Larrota, M. A. (2019). Evidencias de reparaciones prehispánicas en la cerámica: estudios recientes en la colección del Museo del Oro. Boletín Museo Del Oro, 58(100-153).

Sassanelli, C., Urbinati, A., Rosa, P., Chiaroni, D., \& Terzi, S. (2020). Addressing circular economy through design for $X$ approaches: A systematic literature review. Computers in Industry, 120, 103245. https://doi.org/10.1016/j.compind.2020.103245

Sumter, D., de Koning, J., Bakker, C., \& Balkenende, R. (2020). Circular Economy Competencies for Design. Sustainability, 12(4), 1561. https://doi.org/10.3390/su12041561

Svensson-Hoglund, S., Richter, J. L., Maitre-Ekern, E., Russell, J. D., Pihlajarinne, T., \& Dalhammar, C. (2021). Barriers, enablers and market governance: A review of the policy landscape for repair of consumer electronics in the EU and the U.S. Journal of Cleaner Production, 288, 125488. https://doi.org/10.1016/j.jclepro.2020.125488

Winwins Argentina. (2017). Club de Reparadores [Video]. Retrieved from https://www.youtube.com/watch?v=hyJcrOHlp8M

Yin, R. K. (2012). Case study methods. In APA handbook of research methods in psychology, Vol 2: Research designs: Quantitative, qualitative, neuropsychological, and biological. (pp. 141-155). https://doi.org/10.1037/13620-009 
Author Bios:

Ricardo J Hernandez is currently Assistant Professor at DILAB School of Engineering and School of Design - Pontificia Universidad Católica de Chile. Previously, he was Research Associate and Lecturer in Design and Innovation at ImaginationLancaster within Lancaster University, UK. His research interests cover sustainable design, innovation, design process, and digital fabrication.

Julian Goñi is a psychologist specialized in interdisciplinary research. As a lecturer and researcher at the Engineering Design Initiative, Universidad Católica de Chile (DILAB UC), he researches the intersection between engineering design, social research and responsible innovation.

Tracy Bhamra is Senior Vice-Principal and Professor of Design for Sustainability at Royal Holloway, University of London. Her research focusses on Methods and Tools for Sustainable Design, Sustainable Product Service Systems and Design for Sustainable Behaviour. 